\title{
Fluorescence approach to evaluating conformational changes upon binding of $\beta$-spectrin ankyrin-binding domain mutants with the lipid bilayer
}

\author{
Grzegorz Pazdzior ${ }^{1}$, Anna Chorzalska ${ }^{2}$, Aleksander Czogalla ${ }^{2}$, Tomasz Borowik ${ }^{1}$, Aleksander \\ F. Sikorski ${ }^{2,3}$ and Marek Langner ${ }^{1,3}$ \\ ${ }^{1}$ Institute of Biomedical Engineering and Instrumentation, Wroclaw University of Technology, Poland \\ ${ }^{2}$ Laboratory of Cytobiochemistry, Biotechnology Faculty, University of Wroclaw, Poland \\ ${ }^{3}$ Academic Centre for Biotechnology of Lipid Aggregates, Wroclaw, Poland
}

\begin{abstract}
The major component of the cell membrane skeleton, spectrin, is anchored in the cell membrane via interactions with membrane proteins. It has been previously shown that both erythroid and non-erythroid spectrin interact directly with membrane phospholipids (mainly aminophospholipids). One of the binding sites responsible for these interactions is located in the ankyrin-binding domain. In the present study, in order to better understand the character of binding, a more detailed investigation of the interactions between the $\beta$-spectrin fragments corresponding to the truncated mutants of the ankyrin-binding domain (Frag1 and Frag3) and liposomes of different compositions were carried out. The obtained results suggest that the binding of both spectrin fragments with liposomes induces conformational changes within the protein. Analysis of the changes in intrinsic tryptophan fluorescence spectra upon binding with liposomes, together with quenching studies (from the water and membrane hydrocarbon environment), allows for qualitative description of changes in proteins conformation. Our results suggest that the largest conformational changes occur for Frag1 bound to PC : PE $(2: 3)$ liposomes what is consistent with previous studies on monolayers. They are also in good agreement with those obtained previously for native erythroid and nonerythroid spectrin molecules.
\end{abstract}

Key words: Spectrin — Liposomes - Fluorescence - Quenching — Ankyrin-binding domain

\section{Introduction}

Spectrin, a high molecular weight flexible rod-like protein formed by the head-to-head association of two antiparallel heterodimers composed of $\alpha(280 \mathrm{kD})$ and $\beta(247 \mathrm{kD})$ subunits is a major component of the dense, well organised protein network called the membrane skeleton (Sahr et al. 1990; Winkelmann et al. 1990). The remarkable mechanical properties of the red blood cell membrane stem from the presence of this structure on the erythrocyte membrane cytoplasmic surface. The detailed structure of the spectrin molecule has not yet been solved, although many structural details based on the structure of the triple-helical segment, the major structural

Correspondence to: Marek Langner, Institute of Biomedical Engineering and Instrumentation, Wroclaw University of Technology, Wybrzeze Wyspianskiego 27, 50-370 Wroclaw, Poland E-mail: marek.langner@pwr.wroc.pl motif of the molecule that is 106 amino acid residues long, was solved, providing background for studying the mechanical properties of this protein (and the membrane skeleton) also in pathological membranes (Yan et al. 1993; Djinovic-Carugo et al. 1999; Grum et al. 1999; Discher and Carl 2001; Zhang et al. 2001). Five to six spectrin heterotetramers interact with a short $(37 \mathrm{~nm})$ actin protofilament to form a structure known as the junctional complex (Byers and Branton 1985). The amino terminus of the $\beta$-spectrin contains an actin-binding domain that is nonhomologous to the spectrin repeat (two tandem CH domains) and is conserved among many proteins that belong to the spectrin superfamily (Karinch et al. 1990; Hartwig 1995; Djinovic-Carugo et al. 1999). Several other proteins - protein 4.1, adducin, dematin, p55, tropomyosin, and tropomodulin - are also involved in forming the junction. The formation of spectrin tetramers (i.e., dimer-dimer interaction) and the junctional complex is responsible for the planar integrity of the membrane skeleton. 
The membrane skeleton of the red blood cell is attached to the lipid bilayer with embedded integral membrane proteins via two interaction pathways, i.e. spectrin-ankyrinAE1(band 3) protein (Bennett and Branton 1977; Bennett and Stenbuck 1979; Yu and Goodman 1979; Bennett and Stenbuck 1980) and protein 4.1-glycophorin C and D (Pinder et al. 1993) and the ternary interaction protein 4.1-p55-glycophorin C (Hemming et al. 1995), or recently discovered connection involving Rh, RhAG, CD47, protein 4.2 and/or ankyrin (Mouro-Chanteloup et al. 2003; Nicolas et al. 2003).

There are, however, many indications even predating studies on protein-protein interactions in cells, isolated membranes, and model systems that direct protein-lipid interactions contribute to the attachment of the membrane skeleton to the membrane hydrophobic domain (Grzybek et al. 2006; Sikorski et al. 2008). The systematic studies of An et al. (2004) indicate several phosphatidylserine (PS)-binding sites along $\alpha$ - and $\beta$-spectrin molecules. On the other hand, our data (Bialkowska et al. 1994; Diakowski et al. 1999) on spectrin-lipid interactions indicate the existence of an ankyrin-sensitive phosphatidylethanolamine (PE)rich mono- and bilayer binding site. The $\mathrm{N}$-terminal region of this domain was inferred in this activity (HryniewiczJankowska et al. 2004). Our fluorescence quenching studies carried out on erythrocyte and brain spectrins indicated the strongest effect of $\mathrm{PE} /$ phosphatidylcholine (PC) liposomes (Sikorski et al. 1987; Michalak et al. 1993).

In the present report, we study the effect of phospholipid vesicles on spectrin intrinsic (tryptophan) fluorescence in more detail and in quantitative terms. In particular, the fragments of the ankyrin-binding domain (ankBD) of erythroid $\beta$-spectrin are suitable as they are of relatively low molecular weight and contain few tryptophan residues. Moreover, it has already been determined that one of them, Frag1, contains an ankyrinsensitive lipid-binding site while in the other this site was impaired. Our fluorescence study revealed that upon binding to liposomes both investigated spectrin fragments may undergo conformational changes. Quantitative calculations were possible due to the fact that the intrinsic tryptophan fluorescence of both fragments was altered upon the addition of liposomes. The observed decrease in fluorescence intensity may result from an interaction between the tryptophan and neighbouring residues (Callis and Liu 2004). A fluorescence quenching study suggests that upon a liposome binding tryptophan residues of both proteins are located in a more hydrophilic environment compared to that when proteins are in an aqueous phase (a higher Stern-Volmer constant for proteins bound to liposomes). Bigger changes in fluorescence intensity could be observed for the interactions of Frag1 with PC: PE $(2: 3)$ liposomes. Such a result is consistent with previous studies on monolayers and with previously performed studies on native spectrins (Sikorski et al. 1987; Diakowski et al. 1999). These studies were, however, only qualititative as high molecular weight spectrin molecule contains multiple tryptophan residues.

\section{Materials and Methods}

Egg PC, brain PS and PE, and 5-doxyl-stearic acid (5DOXYL) were purchased from Avanti Polar Lipids, Inc., (Alabaster, AL, USA). All other chemicals were of analytical or reagent grade. The buffer used in all experiments was 20 $\mathrm{mmol} / \mathrm{l}$ Tris, $150 \mathrm{mmol} / \mathrm{l} \mathrm{NaCl}, \mathrm{pH}$ 7.4. Truncated mutants of the ankBD of erythrocyte $\beta$-spectrin - Frag1 and Frag3 - were constructed as described elsewhere (HryniewiczJankowska et al. 2004).

\section{Protein purification}

Recombinant proteins were expressed in a bacterial expression system by using isopropyl $\beta$-D-thiogalactoside as an inducer for $3 \mathrm{~h}$ at $37^{\circ} \mathrm{C}$, extracted with $8 \mathrm{~mol} / \mathrm{l}$ urea and 100 $\mathrm{mmol} / \mathrm{l} \mathrm{NaCl}$ in $20 \mathrm{mmol} / \mathrm{l}$ Tris/HCl, $\mathrm{pH}$ 8.0, and purified by immobilized $\mathrm{Co}^{2+}$-affinity chromatography (Clontech). After purification, proteins were dialyzed for $3 \mathrm{~h}$ in 20 $\mathrm{mmol} / \mathrm{l}$ Tris/HCl, $150 \mathrm{mmol} / \mathrm{l} \mathrm{NaCl}, \mathrm{pH} 7.7$ and overnight in $20 \mathrm{mmol} / \mathrm{l}$ Tris/ $\mathrm{HCl}, 150 \mathrm{mmol} / \mathrm{l} \mathrm{NaCl}, \mathrm{pH}$ 7.4. The purity of the proteins was analyzed using electrophoresis. The concentration of both proteins was measured by absorption at $280 \mathrm{~nm}$. Extinction coefficients were calculated for each protein using the ProtParam tool from the Expasy web page (http://expasy.org/tools/protparam.html).

\section{Preparation of vesicles}

The required volumes of chloroform lipid solutions were mixed in a glass tube. The solvent was evaporated under a stream of nitrogen. The dry lipid film was placed overnight in vacuum and then suspended in $20 \mathrm{mmol} / \mathrm{l}$ Tris/ $\mathrm{HCl}, 150$ $\mathrm{mmol} / \mathrm{l} \mathrm{NaCl}$, pH 7.4 buffer. Large unilammelar vesicles were prepared by extruding 50 times through $100 \mathrm{~nm}$ polycarbonate filters (Nucleopore track-etched membranes, Whatman).

\section{Calculation of protein-membrane partition coefficients}

Fluorescence intensity measurements of tryptophan residues in proteins were performed using a CarryEclipse (Varian) spectrofluorimeter. The excitation wavelength was $295 \mathrm{~nm}$. Fluorescence emission was measured at $350 \mathrm{~nm}$. The excitation and emission slits were set to 5 and $10 \mathrm{~nm}$, respectively. Fluorescence intensities of samples were measured in $10 \times$ $10 \mathrm{~mm}$ quartz cuvette placed in a thermo-regulated Pel- 
tier cuvette holder $\left(25^{\circ} \mathrm{C}\right)$. In the partitioning experiments protein concentrations were kept constant and highly concentrated liposomes were injected into the protein solution (three independent experiments with different protein concentrations; for each 6-10 liposomes injections). Collected fluorescence intensities were corrected for the light scattering effect (Ladokhin et al. 2000). The mole-fraction partition coefficient was calculated according to the following equation (Ladokhin 1999; Ladokhin et al. 2000):

$$
F([L])=1+\left(F_{\infty}-1\right) \frac{K_{X}[L]}{K_{X}[L]+[W]}
$$

where $K_{x}$ is a mole-fraction partition coefficient defined as:

$$
K_{x}=\frac{\left[P_{\text {bil }}\right] /\left([L]+\left[P_{\text {bil }}\right]\right)}{\left[P_{\text {water }}\right] /\left([W]+\left[P_{\text {water }}\right]\right)}
$$

where $\left[P_{b i l}\right]$ and $\left[P_{\text {water }}\right]$ are the bulk molar concentrations of peptides associated with the membrane and remaining in the water phases, respectively, and $[L]$ and $[W]$ are the molar concentrations of lipid and water, $F$ is the fluorescence intensity after the addition of liposomes, and $F_{\infty}$ is the fluorescence increase upon complete binding. The calculated partition coefficient was used to evaluate water-to-bilayer mole-fraction free energies of protein transfer for Frag1 and Frag3 into liposomes of different compositions according to the equation:

$$
\Delta G=-\mathrm{R} T \ln K_{X}
$$

where $\mathrm{R}$ is the gas constant and $\mathrm{T}$ is the temperature. All data were analyzed using OrginPro 7.5 software.

\section{Fluorescence quenching measurements}

Fluorescence quenching measurements with a membrane quencher (5-DOXYL) and an aqueous phase quencher (KI and $\mathrm{CsF}$ ) were performed using a Hitachi spectrofluorimeter. Both hydrophobic and hydrophilic quencher concentrations were within the limits which ensure membrane stability (Lakowicz 1999). Emission scans were performed starting from $310 \mathrm{~nm}$ up to $450 \mathrm{~nm}$ with $295 \mathrm{~nm}$ excitation wavelength. Both emission and excitation slits were $5 \mathrm{~nm}$ and the temperature was $25^{\circ} \mathrm{C}$. Spectra were measured using a $10 \times 10 \mathrm{~mm}$ cuvete, corrected for light scattering and fitted with a log-normal distribution function (Ladokhin 1999; Ladokhin et al. 2000):

$$
F(\lambda)= \begin{cases}F_{0} \exp \left(\frac{\ln 2}{\ln ^{2} \rho} \ln ^{2}\left(1+\frac{\left(\lambda-\lambda_{\text {max }}\right)\left(\rho^{2}-1\right)}{\rho \Gamma}\right)\right) & \text { for } \lambda>\lambda_{\text {max }}-\frac{\rho \Gamma}{\rho^{2}-1} \\ 0 & \text { for } \lambda<\lambda_{\max }-\frac{\rho \Gamma}{\rho^{2}-1}\end{cases}
$$

Three parameters were used for a subsequent data analysis: the position of the fluorescence maximum $\left(\lambda_{\max }\right)$, the fluorescence intensity in $\lambda_{\max }\left(F_{\max }\right)$, and the full width of the spectrum at half-maximum intensity $\mathrm{F}_{\max / 2}(\Gamma)$. Parameter $\rho$ describes skewness of the distribution and was not used in any further analysis. Quenching was assumed to be dynamic and experimental data were analyzed using the Stern-Volmer equation (Lakowicz 1999):

$$
\frac{F_{0}}{F}=1+\mathrm{K}_{\mathrm{SV}}[\mathrm{Q}]
$$

where $F_{0}$ and $F$ are fluorescence intensities in the absence and in presence of the quencher, respectively, $\mathrm{K}_{\mathrm{SV}}$ is the SternVolmer quenching constant, and $[\mathrm{Q}]$ is the concentration of the quencher in the sample. Each quenching experiment was performed 3 times.

\section{Results}

\section{The protein-membrane partition coefficient}

The addition of liposomes to solutions containing each of investigated proteins result with a decrease in the fluorescence intensity without a shift in the position of tryptophan fluorescence maximum. Such an effect may result from a decreased tryptophan quantum yield or from a quenching by nearby amino-acid residues upon conformational changes in the proteins (Callis and Liu 2004). We assume that the decrease in fluorescence intensity at a constant wavelength can be used as a measure of the protein binding (Ladokhin et al. 2000). In these studies, the following liposomes compositions were used: PC, PC : PE (2:3), PC : PS ( $2: 3)$ and PE : PS (1: 1$)$. All lipid mixtures formed stable liposomes (Langner and Kubica 1999). Obtained results are presented in Fig. 1.

The calculated protein-membrane $K_{x}$ enables the calculation of water-to-bilayer mole-fraction free energies of protein transfer for Frag1 and Frag3 into liposomes (Table 1). It is worth noting that the data obtained for Fragl, unlike these for Frag3, are in good agreement with those obtained for native red blood cell or neuronal spectrin molecules (Sikorski et al. 1987; Diakowski et al. 1999) with respect to the effect exerted by PC/PE liposomes.

\section{The effect of liposomes of different compositions on the intrinsic tryptophan fluorescence for Frag1 and Frag3}

The $\lambda_{\max }$ (position of the tryptophan fluorescence maximum) in proteins varies over a $40-\mathrm{nm}$ range, depending on the polarity and rigidity of the local environment. According to the model of discrete states (Burstein et al. 1973; Lakowicz 1999), there are five probable spectral forms of tryptophan residues: two with structured spectra (classes 

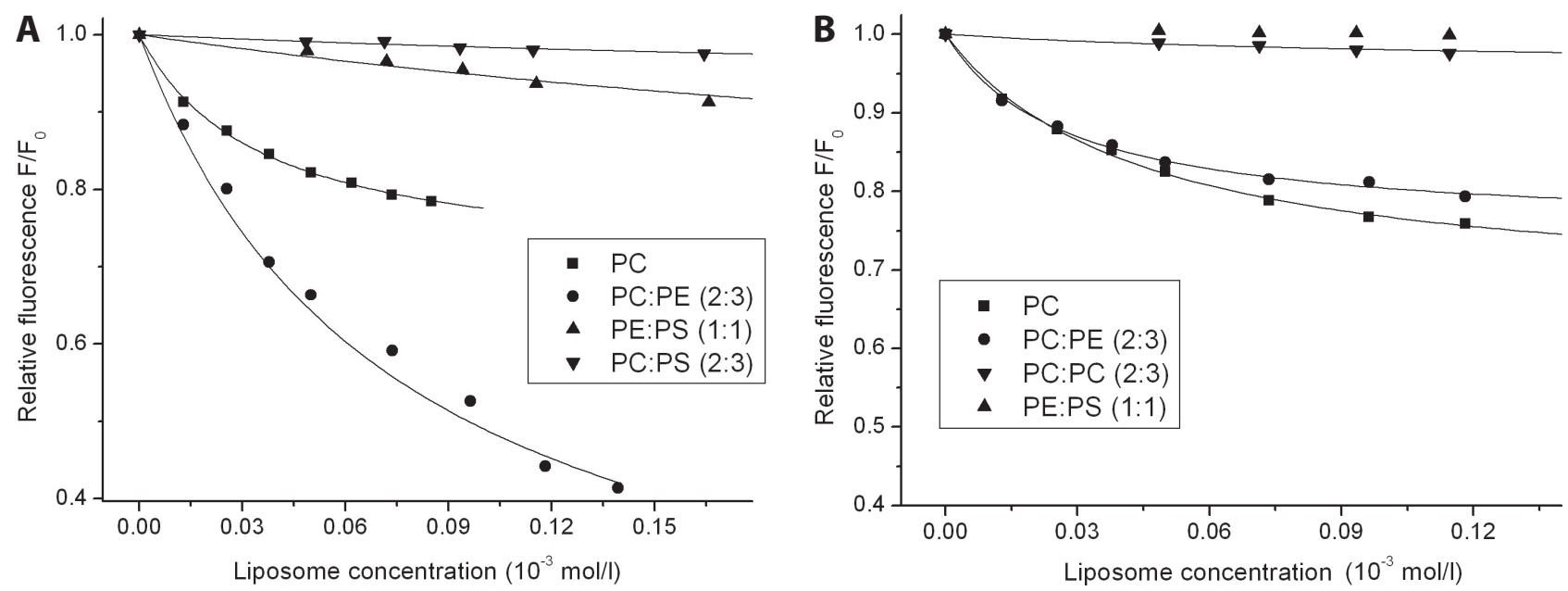

Figure 1. Small portions (usually $10 \mu \mathrm{l}$ ) $1 \mathrm{mg} / \mathrm{ml}$ liposomes of different compositions were injected into a buffer solution of $300 \times 10^{-9}$ $\mathrm{mol} / \mathrm{l}$ Frag1 (A), $330 \times 10^{-9} \mathrm{~mol} / \mathrm{l} \mathrm{Frag} 3$ (B). After $10 \mathrm{~min}$ the fluorescence was measured - as described in Materials and Methods. The relative fluorescence was calculated using $F_{0}$ as the fluorescence without liposomes. Solid lines represent the best fit according to Eq. (1), with $K_{x}$ and $I_{\infty}$ as parameters.

Table 1. Calculated mole-fraction partition coefficients of Frag1 and Frag3 as a function of membrane composition

\begin{tabular}{|l|c|c|c|c|c|c|}
\hline \multirow{2}{*}{} & \multicolumn{3}{|c|}{ PC } & \multicolumn{3}{c|}{ PC : PE $(2: 3)$} \\
\cline { 2 - 7 } & $K_{x}\left(10^{3}\right)$ & $I_{\infty}$ (a.u.) & $\Delta G(\mathrm{kcal} / \mathrm{mol})$ & $K_{x}\left(10^{3}\right)$ & $I_{\infty}$ (a.u.) & $\Delta G(\mathrm{kcal} / \mathrm{mol})$ \\
\hline Frag1 & $85 \pm 17$ & $0.69 \pm 0.1$ & $-6.72 \pm 0.1$ & $41 \pm 2$ & $0.11 \pm 0.2$ & $-6.28 \pm 0.05$ \\
\hline Frag3 & $67 \pm 9$ & $0.66 \pm 0.1$ & $-6.58 \pm 0.1$ & $109 \pm 21$ & $0.75 \pm 0.2$ & $-6.86 \pm 0.1$ \\
\hline & \multicolumn{3}{|c|}{ PC: PS $(2: 3)$} & \multicolumn{3}{c|}{ PS : PE $(1: 1)$} \\
\cline { 2 - 7 } & $K_{x}\left(10^{3}\right)$ & $I_{\infty}$ (a.u.) & $\Delta G(\mathrm{kcal} / \mathrm{mol})$ & $K_{x}\left(10^{3}\right)$ & $I_{\infty}$ (a.u.) & $\Delta G(\mathrm{kcal} / \mathrm{mol})$ \\
\hline Frag1 & $8 \pm 1$ & $0.91 \pm 0.2$ & $-5.32 \pm 0.2$ & $6 \pm 0.8$ & $0.70 \pm 0.2$ & $-5.15 \pm 0.1$ \\
\hline Frag3 & $24 \pm 5$ & $0.96 \pm 0.2$ & $-5.97 \pm 0.15$ & $\mathrm{n} / \mathrm{d}$ & $\mathrm{n} / \mathrm{d}$ & $\mathrm{n} / \mathrm{d}$ \\
\hline
\end{tabular}

$K_{x}$, the obtained mole-fraction partition coefficient of both proteins (when titrated with liposomes); $I_{\infty}$, the relative fluorescence decrease upon complete binding; $\Delta G$, the water-to-bilayer mole-fraction free energy of protein transfer into liposomes, calculated as described in Materials and Methods.

A and S) and three with unstructured spectra (classes I, II and III) related to the degree of water exposure (Lakowicz 1999). The fluorescence wavelength maximum and spectral width can be used to estimate conformational heterogeneity in a variety of systems, including membrane-bound proteins. The estimation takes advantage of the fact that the spectral width of tryptophan fluorescence in a homogeneous environment depends linearly on the fluorescence wavelength maximum. Any deviation from linearity can be interpreted as heterogeneity of a tryptophan population. In order to be able to extract information from tryptophan spectra, they have to be corrected by using the following equation (Ladokhin et al. 2000):

$$
F_{\text {protein }}^{\text {corrected }}(\lambda)=F_{\text {protein }}^{\text {uncorrected }}(\lambda) \frac{F_{\text {ref }}^{S L M}(\lambda)}{F_{\text {ref }}^{\text {uncorrected }}(\lambda)}
$$

where $F_{\text {protein }}^{\text {unceded }}(\lambda)$ is the measured protein spectrum, $F_{\text {ref }}^{\text {SLM }}(\lambda)$ is the tryptophan reference spectrum, and $F_{\text {ref }}^{\text {uncorrected }}(\lambda)$ is the measured tryptophan spectrum.

After the correction, the spectra were fitted according to Eq. (3). For each spectrum, two parameters were evaluated: $\lambda_{\max }$ and $\Gamma\left(\lambda_{\max }\right)$ and plotted in Fig. 2 . As a baseline, the following equation was used:

$\Gamma\left(\lambda_{\max }\right)=-156.7+0.624 \lambda_{\max }$

The presented results show that tryptophan residues in both proteins are located in a heterogeneous environment. The positions of the spectral parameters of Frag1 and Frag3 (without liposomes) do not depend on protein concentration (data not shown), whereas the addition of liposomes changes the position of spectral parameters, which suggest conformational changes in proteins upon binding. 


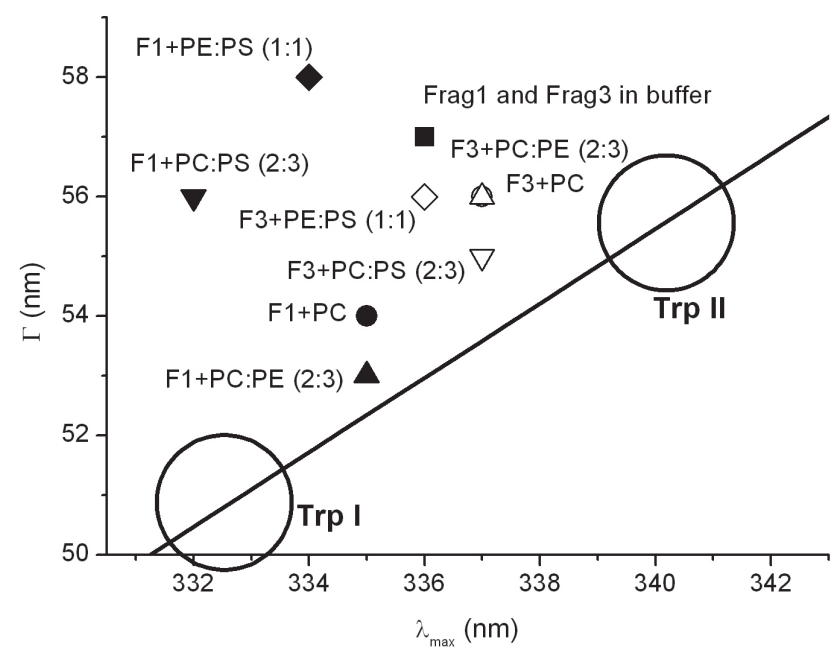

Figure 2. Analysis of the spectral parameters of Frag1 and Frag3 for free proteins in a buffer and proteins bound to liposomes of different composition. Large circles, labeled Trp I and Trp II, show the classes of tryptophan residues that correlate roughly with the extent of exposure to water. Tryptophan residues, which are partially shielded from the aqueous phase, belong to class Trp II, whereas residues that are completely buried belong to class Trp I. Solid symbols represent Frag1, open symbols represent Frag3. F1, Frag1; $F 3$, Frag3; $\Gamma$, spectral width; $\lambda_{\text {max }}$, position of the tryptophan fluorescence maximum.

\section{Tryptophan quenching from the aqueous phase}

Intrinsic tryptophan fluorescence was quenched from the aqueous phase by $\mathrm{I}^{-}$and $\mathrm{Cs}^{+}$ions. Small volumes of $2 \mathrm{~mol} / \mathrm{l} \mathrm{KI}$ and $2 \mathrm{~mol} / \mathrm{l} \mathrm{CsF}$ (usually $10 \mu \mathrm{l}$ ) were added into a buffer solution containing a mixture of Frag1 or Frag3 with liposomes of different compositions. Ten minutes after each addition of the quencher, the spectrum of intrinsic tryptophan fluorescence was measured as described in the Materials and Methods section. To avoid osmotic imbalance, only a small salt concentration range was investigated $(0-0.2 \mathrm{~mol} / \mathrm{l})$. No significant deviation from the linear dependence of $F_{0} / F$ vs. [KI] or [CsF] was observed (data not shown), and therefore only the standard Stern-Volmer equation (Eq. (4)) was applied for fitting the data. As shown in Fig. 1, the presence of liposomes causes a decrease in the protein intrinsic fluorescence. Therefore, $F_{0}$ is the fluorescence intensity in the presence of liposomes and the calculated $\mathrm{K}_{\mathrm{SV}}$ corresponds only to quenching by $\mathrm{I}^{-}$and $\mathrm{Cs}^{+}$ions. Results are presented in Fig. 3.

When $\mathrm{I}^{-}$ions are present in solution containing proteins associated with liposomes, significantly higher $\mathrm{K}_{\mathrm{SV}}$ could be observed compared to the proteins in the buffer. On the other hand, when $\mathrm{Cs}^{+}$ions are present, calculated $\mathrm{K}_{\mathrm{SV}}$ is slightly smaller for proteins bound to liposomes compared to proteins in the buffer. Also $\mathrm{K}_{\mathrm{SV}}$ constant for both proteins in the buffer calculated for $\mathrm{I}^{-}$ions is higher than for $\mathrm{Cs}^{+}$.

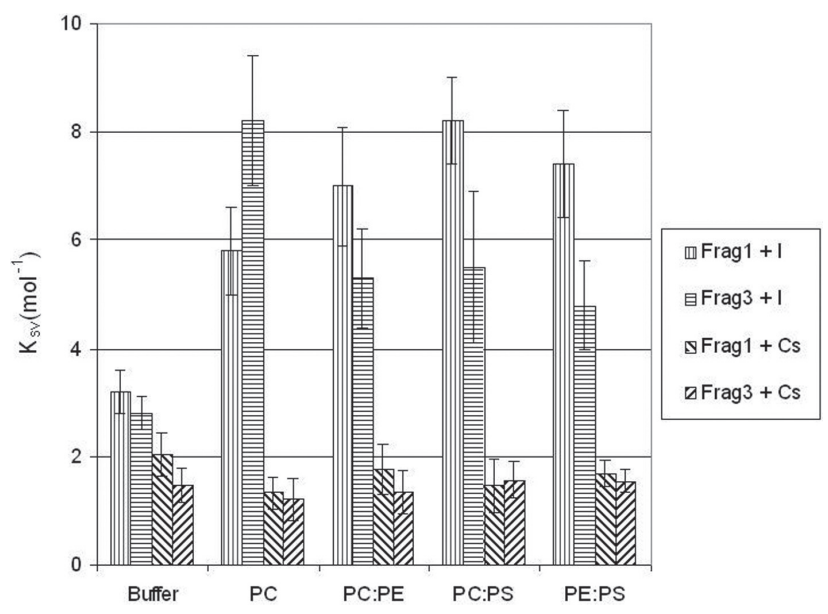

Figure 3. Stern-Volmer constants $\left(\mathrm{K}_{\mathrm{SV}}\right)$ for quenching with $\mathrm{I}^{-}$calculated for Frag1 (bars with vertical lines) and Frag3 (bars with horizontal lines) and for $\mathrm{Cs}^{+}$calculated for Frag1 (bars with negative skewness) and Frag3 (bars with positive skeness) in different media: buffer only and in the presence of liposomes of the following compositions: PC, PC: PE (2:3), PC: PS (2:3), and PE : PS (1:1). For each liposome composition, experiments were performed three times (the standard deviation is indicated).

Such results may suggest that binding of both proteins to the liposomes causes some conformational changes in the proteins. Opposite effect of $\mathrm{Cs}^{+}$and $\mathrm{I}^{-}$ions quenching as express by values of $\mathrm{K}_{\mathrm{SV}}$ may indicate that tryptophan residues are not shielded from the aqueous phase when associated with the membrane surface and that there are electrostatic charges in the vicinity of the tryptophan residue. Elevated values of $\mathrm{K}_{\mathrm{SV}}$ for $\mathrm{I}^{-}$ions may indicate that residues with positive charges are located in the vicinity of tryptophan after a protein binding to liposome. Such an explanation is consistent with a decrease in $\mathrm{K}_{\mathrm{SV}}$ in the presence of $\mathrm{Cs}^{+}$ions (McLaughlin 1989; Lakowicz 1999).

Intrinsic tryptophan fluorescence quenching by the membrane quencher 5-DOXYL-stearic acid

Additional information about conformational changes can be obtained when not only an aqueous quencher, but also a membrane-located quencher is used. For this purpose, 10 mol\% of 5-DOXYL was incorporated into liposomes of various composition. The amount of the membrane quencher ensures the high quenching efficiency without the extensive bilayer perturbation (Lakowicz 1999). It is assumed that for such a concentration quenching is mostly static (Chattopadhyay and London 1987). For simplicity, the data in Fig. 4 represents only the calculated relative tryptophan fluorescence $F / F_{0}$, where $F$ is the fluorescence in the presence of liposomes containing 5-DOXYL and $F_{0}$ is the fluorescence in the refer- 


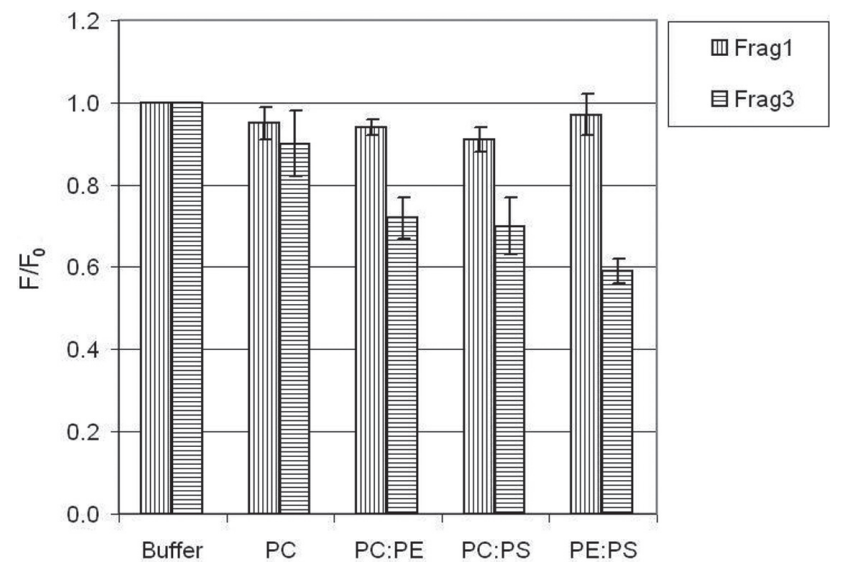

Figure 4. Relative fluorescence (F/F0) of intrinsic tryptophan in Frag1 (bars with vertical lines) and Frag3 (bars with horizontal lines) when incubated with liposomes containing $10 \mathrm{~mol} \%$ of 5-DOXYL relative to the same liposome concentration but without 5-DOXYL. For each liposome composition, three independent experiments were performed. On the figure, standard deviation is shown.

ence sample containing the same liposome concentration and composition but without 5-DOXYL. The data presented in Fig. 4 indicate that the intrinsic fluorescence of Frag1 is quenched by the 5-DOXYL in PC membrane only slightly, whereas its fluorescence was quenched by $30-40 \%$ when associated with aminophospholipid-containing liposomes.

When PC : PE (2:3) liposomes containing $10 \mathrm{~mol} \%$ 5-DOXYL were used, we have observed a blue shift by $2 \mathrm{~nm}$ $\left(\lambda_{\max }=333.7 \mathrm{~nm}\right)$ in the fluorescence spectra maximum and a narrowing of the full width of the spectrum at a halfmaximum intensity by $5 \mathrm{~nm}\left(I_{\max / 2}=52 \mathrm{~nm}\right)$ for Frag 3 - as shown in Fig. 5. Such an effect was not observed for any other liposome composition containing 5-DOXYL and for Frag1. When one analyzes parameters extracted from spectra (as shown in Fig. 2), it can be found that tryptophan spectra belong to the class TrpI (tryptophan residues that are completely buried), indicating the selective quenching of other tryptophan populations.

\section{Discussion}

Both investigated protein fragments, Frag1 and Frag3, are parts of the membrane skeleton protein - spectrin. Frag1 covers repeats 13 (partially), 14 and 15 (partially), and contains three tryptophan residues (all in repeat 14), whereas Frag 3 consists of repeats 14 (partially), 15 and 16 (partially) and contains four tryptophan residues (Fig. 6). Those two proteins have been chosen from a bigger family of spectrin fragments; one of them (Frag1) was previously shown to contain fully active ankyrin-sensitive lipid-binding site while

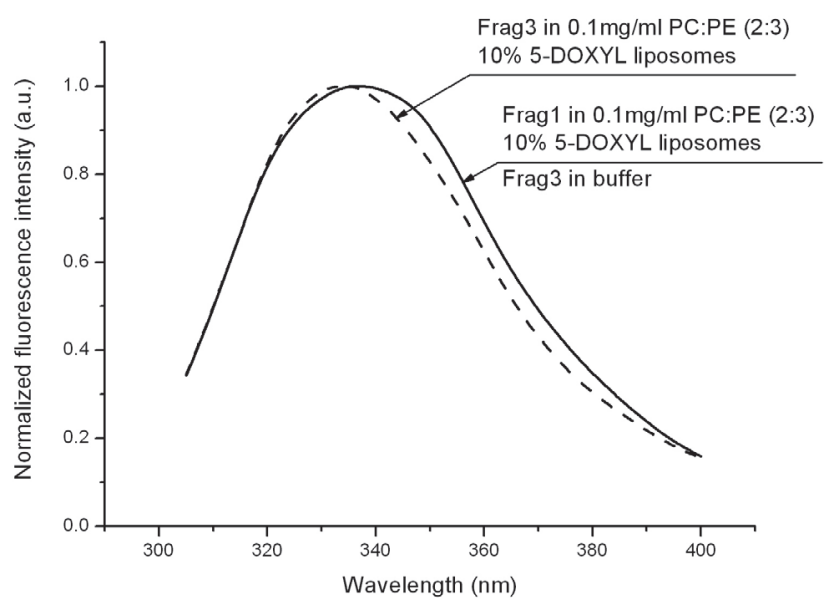

Figure 5. Spectra of the tryptophan fluorescence of Frag1 in $0.1 \mathrm{mg} / \mathrm{ml}$ PC : PE (2:3) $10 \mathrm{~mol} \%$ 5-DOXYL (dotted-line), Frag3 in buffer (solid-line), Frag3 in $0.1 \mathrm{mg} / \mathrm{ml} \mathrm{PC} \mathrm{:} \mathrm{PE}(2: 3) 10 \mathrm{~mol} \%$ 5-DOXYL (dash-line). Spectra of tryptophans in Frag3 in buffer and Frag 1 in $0.1 \mathrm{mg} / \mathrm{ml} \mathrm{PC} \mathrm{:} \mathrm{PE} \mathrm{(2:3)} 10 \mathrm{~mol} \%$ 5-DOXYL overlap and therefore cannot be distinguished. For presentation purposes, the presented spectra were meaningly smoothed.

in the other (Frag3) the lipid-binding site was impaired by 8 residue sequence deletion from original ankyrin-binding domain as was shown in model studies (Hryniewicz-Jankowska et al. 2004) and in studies on cells (Bok et al. 2007).

The measured difference in the overall fluorescence has to be considered as the superposition of changes of all tryptophan fluorescence. It has been previously shown that repeats $15+$ do not bind the membrane (An et al. 2004). Therefore, we assume that the measured differences are mainly due to changes in repeat 14 .

Any change in the tryptophan environment alters its fluorescence spectrum properties. Change in the hydration/ polarity of environment causes not only a shift in position of the tryptophan fluorescence intensity maximum, but also a change in the spectrum width at half-maximum intensity (Lakowicz 1999). Whereas, interactions with neighbouring amino acid residues can alter the tryptophan quantum yield (Callis and Liu 2004). Therefore, investigating changes in the tryptophan spectrum is considered as easy and efficient way to evaluate binding or/and conformational changes in proteins.

It is usual way in biochemistry and enzymology to think about associations among molecules in terms of chemical equilibria, as in the stoichiometric binding of small molecules to specific sites on macromolecules. The preferential association of proteins $(\mathrm{P})$ with lipid $(\mathrm{L})$ vesicles is frequently treated as a simple chemical equilibrium between peptide and lipid molecules: $\mathrm{P}+\mathrm{L} \Leftrightarrow \mathrm{LP}$ or $\mathrm{P}+\mathrm{mL} \Leftrightarrow \mathrm{PmL}$ (the 


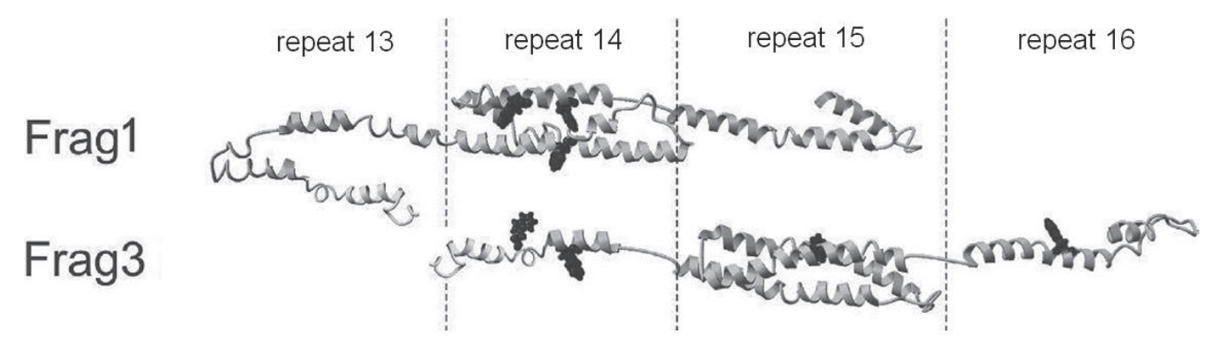

Figure 6. Ribbon structures of Frag1 (residue 1638-1845) and Frag3 (residue 1776-1952) as predicted by the Robetta meta-server (http://robetta.bakterlab.org) and visualized via YASARA (http://www.yasara.org). Tryptophans are visualized as bold atomic structures.

protein is treated as a macromolecule with m binding sites for lipid molecules). Such an approach is quite appropriate for membrane systems when considering the association of ligands with membrane receptors. When applied to the associations of proteins or peptides with the lipid bilayer, however, conceptual difficulties arise (the stoichiometry of interactions does not have to be fixed and hydrophobic and electrostatic interactions that drive most protein-bilayer interactions arise from collective properties and the behavior of lipids in the bilayer). Somewhat similar approach is proposed in the Langmuir isotherm model: instead of binding sites for lipid molecules on a protein, active binding sites on the surface for proteins are proposed: $A+B \Leftrightarrow A B$, where $A$ is a molecule adsorbed on a surface where the active site $\mathrm{B}$ is located. Assumptions of this model are not necessarily correct. Namely, a) adsorption is reversible; b) properties of the protein are constant, even after adsorption; c) there are no lateral interactions between absorbed molecules; $\mathrm{d}$ ) each binding site, $\mathrm{B}$, adsorbs only one A molecule; e) all adsorption sites have the same affinity. Such an approach has been used in previous studies to calculate the dissociation constant of spectrin truncated mutants to model membranes (Hryniewicz-Jankowska et al. 2004). Due to the fluid nature of the membrane and the character of interactions that drive most protein-bilayer binding, the interactions of peptides or proteins should be considered as interactions with a lipid assembly, the bilayer, rather than with the individual molecules it comprises. Reviews can be found in Sikorski et al. (2008). In the present work, $K_{x}$ together with the free energy of protein transfer from water to the bilayer have been calculated (Table 1). Differences between the partition coefficients obtained here and those found in literature can arise from different approaches and different model systems (small unilamelar vesicles were previously used) (An et al. 2004; Hryniewicz-Jankowska et al. 2004). The highest affinity of protein to membrane was observed for Frag3 with PC : PE (2:3) liposomes: $\Delta G=-6.86 \mathrm{kcal} / \mathrm{mol}$. It was not possible to calculate $K_{x}$ for Frag3 with PS : PE (1:1) liposomes due to the small decrease in fluorescence. This can be a result of the small partitioning of Frag3 into liposomes or complex conformational changes (although the quantum yield of each tryptophan changes, the overall fluorescence remains constant). Also results obtained for PC : PS (2:3) have to be consider as approximated (decrease in fluorescence was not statistically relevant). Having in mind, that $F_{\infty}$ (relative decrease in fluorescence upon complete binding) can be interpreted as a measure of conformational changes, it is clearly visible that for PC : PS $(2: 3)$ both proteins remain essentially unchanged ( $F_{\infty}$ close to 1$)$. For PC: PE (2:3), Frag1 demonstrates large conformational change - also when compared to PC liposomes. Therefore, it seems that presence of $\mathrm{PE}$ triggers large conformational changes, but only in Frag1, which affects repeat 14 (Fig. 6). This result seems in line with the results of structural studies (Czogalla et al. 2007, 2008) who although have not observed any changes in the helix content in the $\mathrm{N}$-terminal part of the ankyrin/lipid-binding region but have noticed large change in the inter-helical distance in the region of $14^{\text {th }}$ repeat of Frag1 upon the addition of PC/PE liposomes. This part of the sequence is absent in the Frag3 peptide (compare the scheme presented in Fig. 7).

Besides the decrease in fluorescence intensity, small change in the position of fluorescence maxima and changes in the tryptophan spectra width were observed. This makes possible to analyze the tryptophan residue environment in proteins when they are free in buffer or bound to liposomes (Lakowicz 1999). For proteins in buffer, both fragments reveal a heterogeneous tryptophan environment (spectra are overlapping): some tryptophan residues are fully buried (class I) and some are partially exposed to water (class II) - Fig. 2. Such heterogeneity is caused rather by the presence of different tryptophan residues in proteins than protein aggregation. The addition of liposomes (sufficient for saturation) causes a spectrum shift. For Frag1, the tryptophan residue environment changes in the direction of "burried" residues (closer to class I), whereas for Frag3 it seems that conformational changes rather cause the exposure of tryptophan residues towards solvent. In order to evaluate these changes quantitatively, quenching from an aqueous environment (by $\mathrm{I}^{-}$and $\mathrm{Cs}^{+}$ions) and from the hydrophobic 
membrane core (by 5-DOXYL) was performed. $\mathrm{K}_{\mathrm{SV}}$ for static quenching (Fig. 3) (higher in the presence of liposomes for $\mathrm{I}^{-}$and lower for $\mathrm{Cs}^{+}$ions) suggest that binding to the liposomes causes conformational changes in the proteins that lead to increase in local concentration of positive residues in the vicinity of tryptophans.

A similar pattern to that for the molar partition coefficient can be found: when PC liposomes were used, the fluorescence from Frag3 is quenched more efficiently than the fluorescence from Frag1, whereas when aminophospholipids were incorporated into liposomes, $\mathrm{K}_{\mathrm{SV}}$ for Frag1 is higher than for Frag3. Interesting results are obtained when electrostatic interactions are taken into account and GouyChapman theory is applied (for a review, see McLaughlin 1989; Langner and Kubica 1999) due to the electrostatic interactions between the quencher ion and negative charge of PC : PS and PE : PS liposomes. In brief, the electric surface charge density $\sigma$ at the outer leaflet of vesicles is given by:

$$
\sigma=-\mathrm{e}_{0} \frac{X_{P S}}{X_{P S} A_{P S}+\left(1-X_{P S}\right) A_{a d d}}
$$

where $\mathrm{e}_{0}=1.602 \cdot 10^{-19} \mathrm{C}$ is the elementary charge, $X_{P S}$ denotes the mole fraction of PS in liposomes; $A_{P S}$ and $A_{a d d}$ are the surface area of lipids, respectively, PE and PS for PE : PS liposomes or PC and PE for PC : PS liposomes. For calculations, it was assumed that $A_{P S}=64.1 \AA^{2}$ (value for DOPS (dioleylphosphatidylserine) in fluid phase (McLaughlin 1989)), $A_{P C}=69.4 \AA^{2}$ (value for Egg PC (Nagle and Tristram-Nagle 2000)) and $A_{P E}=51.2 \AA^{2}$ (value for DLPE (dilaurylphosphatidylethanolamine) in fluid phase (Nagle and Tristram-Nagle 2000)). Calculated surface charge densities are respectively: $\sigma_{P C: P S}=-145.1 \mathrm{mC} / \mathrm{m}^{2}$ and $\sigma_{P E}$ : $P S=-138.9 \mathrm{mC} / \mathrm{m}^{2}$ for liposomes composed of PC : PS $(2: 3 \mathrm{~mol} / \mathrm{mol})$ and PE : PS (1: $1 \mathrm{~mol} / \mathrm{mol})$. Knowledge of the membrane surface charge densities allows the calculation of the surface membrane potential $\Psi_{0}$ using Gouy-Chapman theory:

$$
\sigma^{2}=2000 \varepsilon_{0} \varepsilon_{R} \mathrm{R} T \sum_{i} C_{i, e q}\left(\exp \left(-\frac{z_{i} \mathrm{~F}_{0} \Psi_{0}}{\mathrm{R} T}\right)-1\right)
$$

where $\varepsilon_{R}=78$ is the dielectric constant of water (at $25^{\circ} \mathrm{C}$ ), $\varepsilon_{0}$ is the permittivity of free space, $\mathrm{F}_{0}$ is the Faraday constant, $C_{i, e q}$ is the concentration of the $i$-th electrolyte in the bulk aqueous phase (in moles per liter), and $z_{i}$ the signed valence of the $i$-th species. A computer program (Mathematica 5.1) was employed to numerically solve Eq. (7) in respect to surface potential $\Psi_{o}$ from known surface charge density $\sigma$. The effect of a negative membrane surface charge is to repel also negative iodine ion from the membrane surface and to attract positive caesium ions. Assuming, that quenching of Frag1 and Frag3 tryptophans for protein incorporated into liposomes occurs near the membrane surface it is necessary to calculate $\mathrm{I}^{-}$and $\mathrm{Cs}^{+}$concentration $\left(C_{M}\right)$ above the plane of binding according to:

$$
C_{M}=C_{e q} C_{i, e q} \exp \left(-\frac{z_{i} \mathrm{~F}_{0} \Psi_{0}}{\mathrm{R} T}\right)
$$

Numerical data for both, PC : PS $(2: 3 \mathrm{~mol} / \mathrm{mol})$ and PE : PS $(1: 1 \mathrm{~mol} / \mathrm{mol})$ liposomes are presented in Table 2 .

Table 2. Calculated ion concentration directly above the membrane plane, surface membrane potential and surface charge density depending on liposome composition

\begin{tabular}{|c|c|c|c|c|c|c|}
\hline \multirow{2}{*}{$\begin{array}{c}C_{e q, K I} \\
\left(10^{-3} \mathrm{~mol} / \mathrm{l}\right)\end{array}$} & \multicolumn{3}{|c|}{$\mathrm{PC}: \mathrm{PS}(2: 3 \mathrm{~mol} / \mathrm{mol})$} & \multicolumn{3}{c|}{ PE : PS $(1: 1 \mathrm{~mol} / \mathrm{mol})$} \\
\cline { 2 - 7 } & $\begin{array}{c}\sigma_{P C: P S} \\
\left(\mathrm{mC} / \mathrm{m}^{2}\right)\end{array}$ & $\begin{array}{c}\Psi_{0, P C: P S} \\
(\mathrm{mV})\end{array}$ & $\begin{array}{c}C_{M, K I} \\
\left(10^{-3} \mathrm{~mol} / \mathrm{l}\right)\end{array}$ & $\begin{array}{c}\sigma_{P E: P S} \\
\left(\mathrm{mC} / \mathrm{m}^{2}\right)\end{array}$ & $\begin{array}{c}\Psi_{0, P E: P S} \\
(\mathrm{mV})\end{array}$ & $\begin{array}{c}C_{M, K I} \\
\left(10^{-3} \mathrm{~mol} / \mathrm{l}\right)\end{array}$ \\
\hline 0.0 & -145.1 & -96.6 & 0.0 & -138.9 & -94.5 & 0.0 \\
\hline 18.5 & -145.1 & -91.1 & 0.5 & -138.9 & -89.9 & 0.6 \\
\hline 36.7 & -145.1 & -86.7 & 1.3 & -138.9 & -84.5 & 1.4 \\
\hline 54.5 & -145.1 & -83.0 & 2.2 & -138.9 & -80.9 & 2.3 \\
\hline 72.1 & -145.1 & -79.9 & 3.2 & -138.9 & -77.7 & 3.5 \\
\hline 89.3 & -145.1 & -77.2 & 4.4 & -138.9 & -75.1 & 4.8 \\
\hline 106.2 & -145.1 & -74.8 & 5.8 & -138.9 & -72.7 & 6.3 \\
\hline 122.8 & -145.1 & -72.6 & 7.3 & -138.9 & -70.6 & 7.9 \\
\hline 139.1 & -145.1 & -70.7 & 8.9 & -138.9 & -68.7 & 9.6 \\
\hline 155.2 & -145.1 & -69.0 & 10.5 & -138.9 & -66.9 & 11.4 \\
\hline 170.1 & -145.1 & -67.5 & 12.3 & -138.9 & -65.5 & 13.3 \\
\hline
\end{tabular}

$C_{e q, K I}, \mathrm{KI}$ concentration in bulk aqueous phase; $\sigma_{P C: P S}$, surface charge density of PC : PS (2:3 mol/mol) liposomes; $\Psi_{0, P C: P S}$, surface membrane potential of PC : PS (2:3 mol/mol) liposomes; $C_{M, K I}$, KI concentration above the plane of binding; $\sigma_{P E: P S}$, surface charge density of PE : PS (1:1 mol/mol) liposomes; $\Psi_{0, P E: P S}$, surface membrane potential of PE : PS (1:1 mol/mol) liposomes. 


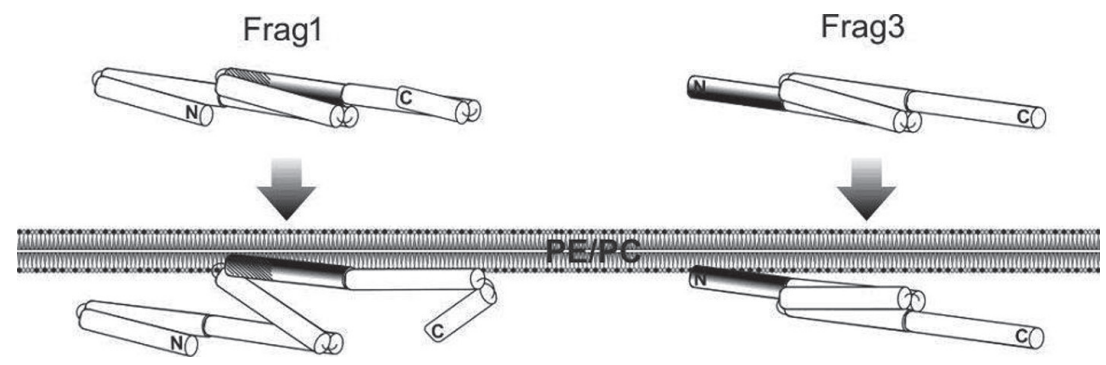

Figure 7. Scheme of the proposed interaction of Frag1 and Frag3 with lipid bilayer of different lipid composition. Frag1 (left) containing full-length PE-rich ankyrin-sensitive lipid-binding domain contains N-terminal amphipathic $3_{10}$ helix and by the other $2 \alpha$-helices of the $14^{\text {th }}$ segment (compare Fig. 6) which upon binding of PE/PC vesicles undergoes substantial changes of the triple-helical conformation (Czogalla et al. 2008). Frag3 which lacks this entire region also undergoes conformational changes but they are much smaller and the lipid specificity is much lower.

For the obtained concentration of $\mathrm{I}^{-}$ions near the membrane, $\mathrm{K}_{\mathrm{SV}}$ was calculated. The obtained values, which are approximately $85 \mathrm{~mol}^{-1}$, are impossible due to the fact that for completely denaturated proteins $\mathrm{K}_{\mathrm{SV}}$ is not higher than $20 \mathrm{~mol}^{-1}$. In order to obtain reasonable $\mathrm{K}_{\mathrm{SV}}$ values $\left(<20 \mathrm{~mol}^{-1}\right)$, quencher concentration in the vicinity of the tryptophan residues has to be higher than calculated. Such results mean that either quenching of tryptophan residues in both proteins takes place at some distance from membrane containing PS (where concentration of $\mathrm{I}^{-}$ions is higher) or the complex conformation of the protein and neighbouring residues attracts negatively charged ions of the quencher.

Except for quenching using a water soluble quencher, tryptophans were quenched from the membrane site using 10 mol\% of 5-DOXYL incorporated into liposomes. Results are presented as relative fluorescence (decrease) when proteins were incubated with liposomes (Fig. 4). It can be observed that for Frag1 there is no significant quenching when the protein is incubated with liposomes, regardless of liposome composition. For Frag3, on the other hand, when aminophospholipids are incorporated into liposomes, tryptophan quenching by 5-DOXYL is significantly higher. This pattern is consistent with previously obtained results: the incorporation of aminophospholipids seems to influence the character of changes in protein conformation.

It has been previously shown that a part of repeat 14 is responsible for the specific binding of spectrin with lipids (namely aminophospholipids) (Hryniewicz-Jankowska et al. 2004). As shown in the present work, the presence of PE or PS in liposomes causes the exposure of Frag1 tryptophans to water, whereas quenching from membrane sites is not affected. The opposite effects of PE and PS on Frag3 can be observed: lower quenching from the aqueous phase and significantly higher from membrane sites. It is clear that the presence of aminophospholipids causes possibly different conformational changes in Frag1 and Frag3. In addition, one should keep in mind that the binding of PE-containing (and to a lesser extend PS-containing) liposomes by Frag1 is ankyrin-sensitive, i.e. purified ankyrin competitively inhibits this binding.

Higher $\mathrm{K}_{\mathrm{SV}}$ for both proteins when tryptophan was quenched by the negative $\mathrm{I}^{-}$ions compared to positive $\mathrm{Cs}^{+}$ions can suggest that tryptophan was localized in the vicinity of positively charged aminoacids $\left(\mathrm{I}^{-}\right.$ions were attracted whereas $\mathrm{Cs}^{+}$ions were repelled). When proteins were bounded to the liposomes, significant increase in the $\mathrm{K}_{\mathrm{SV}}$ for $\mathrm{I}^{-}$ions and small decrease in the $\mathrm{K}_{\mathrm{SV}}$ for $\mathrm{Cs}^{+}$ ions was observed. It can suggest that upon binding to liposomes, the conformation changes of the protein caused displacement of the charged residues rather than burring of the tryptophans into the phospholipids bilayer. The schematic illustration of postulated alterations of Frag1 and Frag3 conformations when exposed to the PE-reach lipid bilayer are presented in Fig. 7. The postulated conformational changes are strongly supported by our studies at near atomic resolution by using site-directed spin labelling method (Czogalla et al. 2007, 2008) and should be confirmed quantitatively by FRET studies on site-directed mutants of these proteins.

It is widely accepted that interactions between spectrin and lipids provide the fluid bilayer with a solid support which significantly increases the mechanical resistance of the cell membrane and thus allowing elastic responses to membrane extension. Moreover, as we proposed previously (Sikorski et al. 1996; Grzybek et al. 2006) ankyrin-sensitive spectrin-lipid interactions would serve as an anchor for spectrin in situations in which ankyrin is either deficient or its affinity for spectrin is reduced. Data from mutant mice (Peters et al. 1992; Southgate et al. 1996; Yi et al. 1997) support this hypothesis.

Acknowledgment. This work was supported by grant 2P04A 02127 from the Polish Ministry of Science and Higher Education. 


\section{References}

An X., Guo X., Sum H., Morrow J., Gratzer W., Mohandas N. (2004) Phosphatidylserine binding sites in erythroid spectrin: location and implications for membrane stability. Biochemistry 43, 310-315; doi:10.1021/bi035653h

Bennett V., Branton D. (1977): Selective association of spectrin with the cytoplasmic surface of human erythrocyte plasma membranes. Quantitative determination with purified (32P) spectrin. J. Biol. Chem. 252, 2753-2763

Bennett V., Stenbuck P. J. (1979): The membrane attachment protein for spectrin is associated with band 3 in human erythrocyte membranes. Nature 280, 468-473; doi:10.1038/280468a0

Bennett V., Stenbuck P. J. (1980): Association between ankyrin and the cytoplasmic domain of band 3 isolated from the human erythrocyte membrane. J. Biol. Chem. 255, 6424-6432

Bialkowska K., Zembron A., Sikorski A. F. (1994): Ankyrin inhibits binding of erythrocyte spectrin to phospholipid vesicles. Biochim. Biophys. Acta 1191, 21-26; doi:10.1016/00052736(94)90228-3

Bok E., Plażuk E., Hryniewicz-Jankowska A., Chorzalska A., Szmaj A., Dubielecka P. M., Stebelska K., Diakowski W., Lisowski M., Langner M., Sikorski A. F. (2007): The lipid-binding role of the $\beta \mathrm{II}$-spectrin ankyrin-binding domain. Cell Biol. Int. 31, 1482-1494; doi:10.1016/ j.cellbi.2007.06.014

Burstein E. A., Vedenkin N., Ivkova M. N. (1973): Fluorescence and location of tryptophan residues in protein molecules. Photochem. Photobiol. 18, 263-279; doi:10.1111/j.17511097.1973.tb06422.x

Byers T. J., Branton D. (1985): Visualization of the protein associations in the erythrocyte membrane skeleton. Proc. Natl. Acad. Sci. U. S. A. 82, 6153-6157; doi:10.1073/ pnas.82.18.6153

Callis P. R., Liu T. Q. (2004): Quantitative prediction of fluorescence quantum yields for tryptophan in proteins. J. Phys. Chem. B 108, 4248-4259; doi:10.1021/jp0310551

Chattopadhyay A., London E. (1987): Parallax method for direct measurement of membrane penetration depth utilizing fluorescence quenching by spin-labeled phospholipids. Biochemistry 26, 39-45; doi:10.1021/bi00375a006

Czogalla A., Grzymajło K., Jezierski A., Sikorski A. F. (2008): Phospholipid-induced structural changes to an erythroid $\beta$-spectrin ankyrin-dependent lipid-binding site. Biochim. Biophys. Acta 1778, 2612-2620; doi:10.1016/ j.bbamem.2008.07.020

Czogalla A., Jaszewski A. R., Diakowski W., Bok E., Jezierski A., Sikorski A. F. (2007): Structural insight into an ankyrin-sensitive lipid-binding site of erythroid $\beta$ spectrin. Mol. Membr. Biol. 24, 215-224; doi:10.1080/ 09687860601102427

Diakowski W., Prychidny A., Swistak M., Nietubyc M., Bialkowska K., Szopa J., Sikorski A. F. (1999): Brain spectrin (fodrin) interacts with phospholipids as revealed by intrinsic fluorescence quenching and monolayer experiments. Biochem. J. 338, 83-90; doi:10.1042/0264-6021:3380083
Discher D. E., Carl P. (2001): New insights into red cell network structure, elasticity, and spectrin unfolding - a current review. Cell. Mol. Biol. Lett. 6, 593-606

Djinovic-Carugo K., Young P., Gautel M., Saraste M. (1999): Structure of the alpha-actinin rod: molecular basis for cross-linking of actin filaments. Cell 98, 537-546; doi:10.1016/S0092-8674(00)81981-9

Grum V. L., Li D., MacDonald R. I., Mondragon A. (1999): Structures of two repeats of spectrin suggest models of flexibility. Cell 98, 523-535; doi:10.1016/S00928674(00)81980-7

Grzybek M., Chorzalska A., Bok E., Hryniewicz-Jankowska A., Czogalla A., Diakowski W., Sikorski A. F. (2006): Spectrin-phospholipid interactions. Existence of multiple kinds of binding sites? Chem. Phys. Lipids 141, 133-141; doi:10.1016/j.chemphyslip.2006.02.008

Hartwig J. H. (1995): Actin-binding proteins. 1: Spectrin super family. Protein Profile 2, 703-800

Hemming N. J., Anstee D. J., Staricoff M. A., Tanner M. J., Mohandas N. (1995): Identification of the membrane attachment sites for protein 4.1 in the human erythrocyte. J. Biol. Chem. 270, 5360-5366; doi:10.1074/jbc.270.10.5360

Hryniewicz-Jankowska A., Bok E., Dubielecka P., Chorzalska A., Diakowski W., Jezierski A., Lisowski M., Sikorski A. F. (2004): Mapping of an ankyrin-sensitive, phosphatidylethanolamine/phosphatidylcholine mono- and bi-layer binding site in erythroid $\beta$-spectrin. Biochem. J. 382, 677-685; doi:10.1042/BJ20040358

Karinch A. M., Zimmer W. E., Goodman S. R. (1990): The identification and sequence of the actin-binding domain of human red blood cell $\beta$-spectrin. J. Biol. Chem. 265, $11833-11840$

Ladokhin A. S. (1999): Evaluation of lipid exposure of tryptophan residues in membrane peptides and proteins. Anal. Biochem. 276, 65-71; doi:10.1006/abio.1999.4343

Ladokhin A. S., Jayasinghe S., White S. H. (2000): How to measure and analyze tryptophan fluorescence in membranes properties, and why bother? Anal. Biochem. 285, 235-245; doi:10.1006/abio.2000.4773

Lakowicz J. R. (1999): Principles of Fluorescence Spectroscopy. Kluwer Academic/Plenum Press, New York

Langner M., Kubica K. (1999): The electrostatics of lipid surfaces. Chem. Phys. Lipids 101, 3-35; doi:10.1016/S00093084(99)00052-3

McLaughlin S. (1989): The electrostatic properties of membranes. Annu. Rev. Biophys. Biophys. Chem. 18, 113-136; doi:10.1146/annurev.bb.18.060189.000553

Michalak K., Bobrowska M., Sikorski A. F. (1993): Interaction of bovine erythrocyte spectrin with aminophospholipid liposomes. Gen. Physiol. Biophys. 12, 163-170

Mouro-Chanteloup I., Delaunay J., Gane P., Nicolas V., Johansen M., Brown E. J., Peters L. L., Le Van Kim C. L., Cartron J. P., Colin Y. (2003): Evidence that the red cell skeleton protein 4.2 interacts with the $\mathrm{Rh}$ membrane complex member CD47. Blood 101, 338-344; doi:10.1182/blood2002-04-1285

Nagle J. F., Tristram-Nagle S. (2000): Structure of lipid bilayers. Biochim. Biophys. Acta 1469, 159-195 
Nicolas V., Le Van Kim C., Gane P., Birkenmeier C., Cartron J. P., Colin Y., Mouro-Chanteloup I. (2003): Rh-RhAG/ankyrin- $\mathrm{R}$, a new interaction site between the membrane bilayer and the red cell skeleton, is impaired by $\mathrm{Rh}$ (null)associated mutation. J. Biol. Chem. 278, 25526-25533; doi:10.1074/jbc.M302816200

Peters L. L., Birkenmeier C. S., Barker J. E. (1992): Fetal compensation of the hemolytic anemia in mice homozygous for the normoblastosis (nb) mutation. Blood 80, 2122-2127

Pinder J. C., Chung A., Reid M. E., Gratzer W. B. (1993): Membrane attachment sites for the membrane cytoskeletal protein 4.1 of the red blood cell. Blood 82, 3482-3488

Sahr K. E., Laurila P., Kotula L., Scarpa A. L., Coupal E., Leto T. L., Linnenbach A. J., Winkelmann J. C., Speicher D. W., Marchesi V. T. (1990): The complete cDNA and polypeptide sequences of human erythroid $\alpha$-spectrin. J. Biol. Chem. 265, 4434-4443

Sikorski A. F., Bialkowska K. (1996): Interactions of spectrins with membrane intrinsic domain. Cell. Mol. Biol. Lett. 1, 97-104

Sikorski A. F., Czogalla A., Hryniewicz-Jankowska A., Bok E., PlazukE., Diakowski W., Chorzalska A., Kolondra A., Langner M., Grzybek M. (2008): Interactions of erythroid and nonerythroid spectrins and other membranes skeletal proteins with lipid mono- and bilayers. In: Advances in Planar Lipid Bilayers and Liposomes, 6 (Ed. A. Leitmannova Liu), pp. 81-104, Elsevier, New York; doi:10.1016/S1554-4516(07)06004-8

Sikorski A. F., Michalak K., Bobrowska M. (1987): Interaction of spectrin with phospholipids. Quenching of spectrin intrinsic fluorescence by phospholipid suspensions.
Biochim. Biophys. Acta 904, 55-60; doi:10.1016/00052736(87)90086-1

Southgate C. D., Chishti A. H., Mitchell B., Yi S. J., Palek J. (1996): Targeted disruption of the murine band 3 gene results in spherocytosis and severe hemolytic anemia despite a normal membrane skeleton. Nat. Genet. 14, 227-230; doi:10.1038/ng1096-227

Winkelmann J. C., Chang J. G., Tse W. T., Scarpa A. L., Marchesi V. T., Forget B. G. (1990): Full-length sequence of the cDNA for human erythroid $\beta$-spectrin. J. Biol. Chem. 265, 11827-11832

Yan Y., Winograd E., Viel A., Cronin T., Harrison S. C., Branton D. (1993): Crystal structure of the repetitive segments of spectrin. Science 262, 2027-2030; doi:10.1126/science.8266097

Yi S. J., Liu S. C., Derick L. H., Murray J., Barkeret J. E., Cho M. R., Palek J., Golan D. E. (1997): Red cell membrane skeleton of ankyrin-deficient $\mathrm{nb} / \mathrm{nb}$ mice lack band 3 tetramers but contain normal skeletons. Biochemistry 36, 9596-9604; doi:10.1021/bi9704966

Yu J., Goodman S. R. (1979): Syndeins: the spectrin-binding protein(s) of the human erythrocyte membrane. Proc. Natl. Acad. Sci. U. S. A. 76, 2340-2344; doi:10.1073/ pnas.76.5.2340

Zhang Z., Weed S. A., Gallagher P. G., Morrow J. S. (2001): Dynamic molecular modeling of pathogenic mutations in the spectrin self-association domain. Blood 98, 1645-1653; doi:10.1182/blood.V98.6.1645

Received: April 16, 2008

Final version accepted: January 14, 2009 